\title{
A SPATIAL GEOGRAPHY OF ABYSSAL TURBULENT MIXING IN THE SAMOAN PASSAGE
}

By Glenn S. Carter, Gunnar Voet, Matthew H. Alford, James B. Girton, John B. Mickett, Jody M. Klymak, Larry J. Pratt, Kelly A. Pearson-Potts, Jesse M. Cusack, and Shuwen Tan 
ABSTRACT. High levels of turbulent mixing have long been suspected in the Samoan Passage, an important topographic constriction in the deep limb of the Pacific Meridional Overturning Circulation. Along the length of the passage, observations undertaken in 2012 and 2014 showed the bottom water warmed by $~ 55$ millidegrees Celsius and decreased in density by $0.01 \mathrm{~kg} \mathrm{~m}^{-3}$. Spatial analysis of this first-ever microstructure survey conducted in the Samoan Passage confirmed there are multiple hotspots of elevated abyssal mixing. This mixing was not just confined to the four main sills-even between sills, the nature of the mixing processes appeared to differ: for example, one sill is clearly a classical hydraulically controlled overflow, whereas another is consistent with mode- 2 hydraulic control. When microstructure casts were averaged into $0.1^{\circ} \mathrm{C}$ conservative temperature classes, the largest dissipation rates and diapycnal diffusivity values ( $>10^{-7} \mathrm{~W} \mathrm{~kg}^{-1}$ and $10^{-2} \mathrm{~m}^{2} \mathrm{~s}^{-1}$, respectively) occurred immediately downstream of the northern sill in the eastern and deepest channel. Although topographic blocking is the primary reason that no water colder than $\Theta=0.7^{\circ} \mathrm{C}$ is found in the western channel, intensive mixing at the entrance sills appeared to be responsible for eroding an approximately $100 \mathrm{~m}$ thick layer of $\Theta<0.7^{\circ} \mathrm{C}$ water. Three examples highlighting weak temporal variability, and hence suggesting that the observed spatial patterns are robust, are presented. The spatial variability in mixing over short lateral scales suggests that any simple parameterization of mixing within the Samoan Passage may not be applicable.

IN PLAIN WORDS. The deepest water in the North Pacific comes from the South Pacific. This northward flow of bottom water is largely blocked by a submarine ridge south of the equator causing the majority of the water to flow through a narrow gap in the ridge, the Samoan Passage. We find that the temperature and salinity of the bottom waters are modified by mixing resulting from a number of complex flowtopography interactions.

\section{INTRODUCTION}

The coldest and deepest water in the North Pacific is not formed locally. The deep limb of the Pacific Meridional Overturning Circulation flows into the North Pacific via the South Pacific deep western boundary current. The densest water in this current has properties consistent with Antarctic Bottom Water, and the upper water has the high-salinity signature of North Atlantic Deep Water (Reid and Lonsdale, 1974; Alford et al., 2013). The majority of this northward transport passes through the $100 \mathrm{~km}$-wide Samoan Passage (white rectangle in Figure 1a). Consequently, turbulent mixing in this choke-point directly affects the density of the bottom water in the North Pacific.

Hydrographic climatologies of bottom temperature (e.g., Gourestski and Koltermann, 2004) show warmer water downstream of the Samoan Passage (Figure 1a). The 1968 Styx expedition observed bottom temperatures of $\theta \lesssim 0.65^{\circ} \mathrm{C}$ to the south and $\theta \gtrsim 0.75^{\circ} \mathrm{C}$ nal surface spanning the North Pacific. Relatively coarse observations were used to infer the existence of accelerated flows (Reid and Lonsdale, 1974), diapycnal mixing rates approaching $10^{-1} \mathrm{~m}^{2} \mathrm{~s}^{-1}$ (Roemmich et al., 1996), and hydraulic control (Freeland, 2001) in the Samoan Passage. Observations from a recent experiment, briefly outlined in the next section, confirmed the presence of abyssal velocities exceeding $0.5 \mathrm{~m} \mathrm{~s}^{-1}$, turbulence levels two to four orders of magnitude above background levels, and hydraulic control points (Alford et al., 2013; Voet et al., 2015; Cusack et al., 2019). Although a significant portion of the bottom temperature modification was observed to occur at a single sill (Alford et al., 2013), dissipation hotspots throughout the passage were inferred from indirect methods (Voet et al., 2015; Cusack et al., 2019). Using density overturn dissipation estimates from long-term moored observations, Cusack et al. (2019) concluded that the mixing was persistent and that the most important influence on dissipation was the interaction of the mean flow with topography. The dissipation rates do not appear to be sensitive to variability in abyssal volume transport through the Samoan Passage (Cusack et al., 2019; Pratt et al., 2019). Tidal effects were measurable in some locations.

The aim of this paper is to use the first microstructure survey in the Samoan Passage to provide a spatial geography of the abyssal turbulent mixing. Three illustrative examples are presented to support the contention that the spatial patterns from our microstructure survey are representative of the typical spatial mixing patterns and processes occurring in the Samoan Passage. (1996) estimated an additional 2.8 Sv flow around the Manihiki Plateau to the east and a $1.1 \mathrm{~Sv}$ flow over the Robbie Ridge to the west. The flow around the Manihiki Plateau was explored further by Pratt et al. (2019).

Pratt et al. (2019) estimated that diapycnal fluxes associated with mixing in the Samoan Passage are greater than the total flux across a typical abyssal isopyc-

\section{OBSERVATIONS}

The Samoan Passage Abyssal Mixing Experiment consisted of three cruises. A short R/V Kilo Moana cruise in 2011 conducted bathymetric mapping and revealed various channels to the west of the main (and deepest) part of the Samoan Passage. The second cruise, RR1209 in 
July-August 2012 aboard R/V Revelle, focused on the larger-scale flow pathways, and the final cruise, TN305 in JanuaryFebruary 2014 aboard R/V Thompson, concentrated on understanding the processes occurring at three key sills identified during the previous cruise. The last two cruises involved a combination of conductivity-temperature-depth (CTD), lowered acoustic Doppler current profiler (LADCP), and turbulent microstructure measurements, along with longand short-term mooring deployments. In total, the experiment resulted in 115 microstructure profiles, data from 13 of which were published in Alford et al. (2013) and Voet et al. (2015). Additionally, there were $143 \mathrm{CTD} / \mathrm{LADCP}$ casts, and 410 hours of towed CTD/LADCP sec- tions (tow-yos) where the instrument was cycled between $\sim 3,500 \mathrm{~m}$ depth and $40 \mathrm{~m}$ above the bottom as the ship traveled at 0.5-0.7 knots. See Voet et al. (2015) for details of the CTD and LADCP setups for RR1209; similar systems and procedures were used for TN305. The TEOS10 equation of state (McDougall and Baker, 2011) is used to calculate conservative temperature $(\Theta)$, absolute salinity (SA), and potential density anomaly referenced to 4,000 dbar $\left(\sigma_{4}\right)$.

The microstructure measurements were made using a 6,000 $\mathrm{m}$ depthrated free-falling Rockland Scientific Vertical Microstructure Profiler (VMP). The untethered VMP dropped ballast weights at a user-defined target pressure to become positively buoyant and return to the surface. Seventy-five percent of the VMP casts were concurrent with CTD/ LADCP casts, with the VMP deployed approximately 15 minutes before the CTD/LADCP. As the VMP descended, airfoil shear probes measured centimeterscale velocity fluctuations (Osborn and Crawford, 1980; Gregg, 1999), and FP07 fast thermistors measured centimeterscale temperature fluctuations (Gregg, 1999). The turbulent kinetic energy dissipation rate, $\varepsilon$, was calculated by integrating the wavenumber spectra derived from $512 \mathrm{~Hz}$ shear measurements (Shay and Gregg, 1986; Peters et al., 1988). Two decibar bins with $50 \%$ overlap were used in the spectral calculation, resulting in an $\varepsilon$ value every $1 \mathrm{db}$. Following Wesson and Gregg (1994), the empiri-
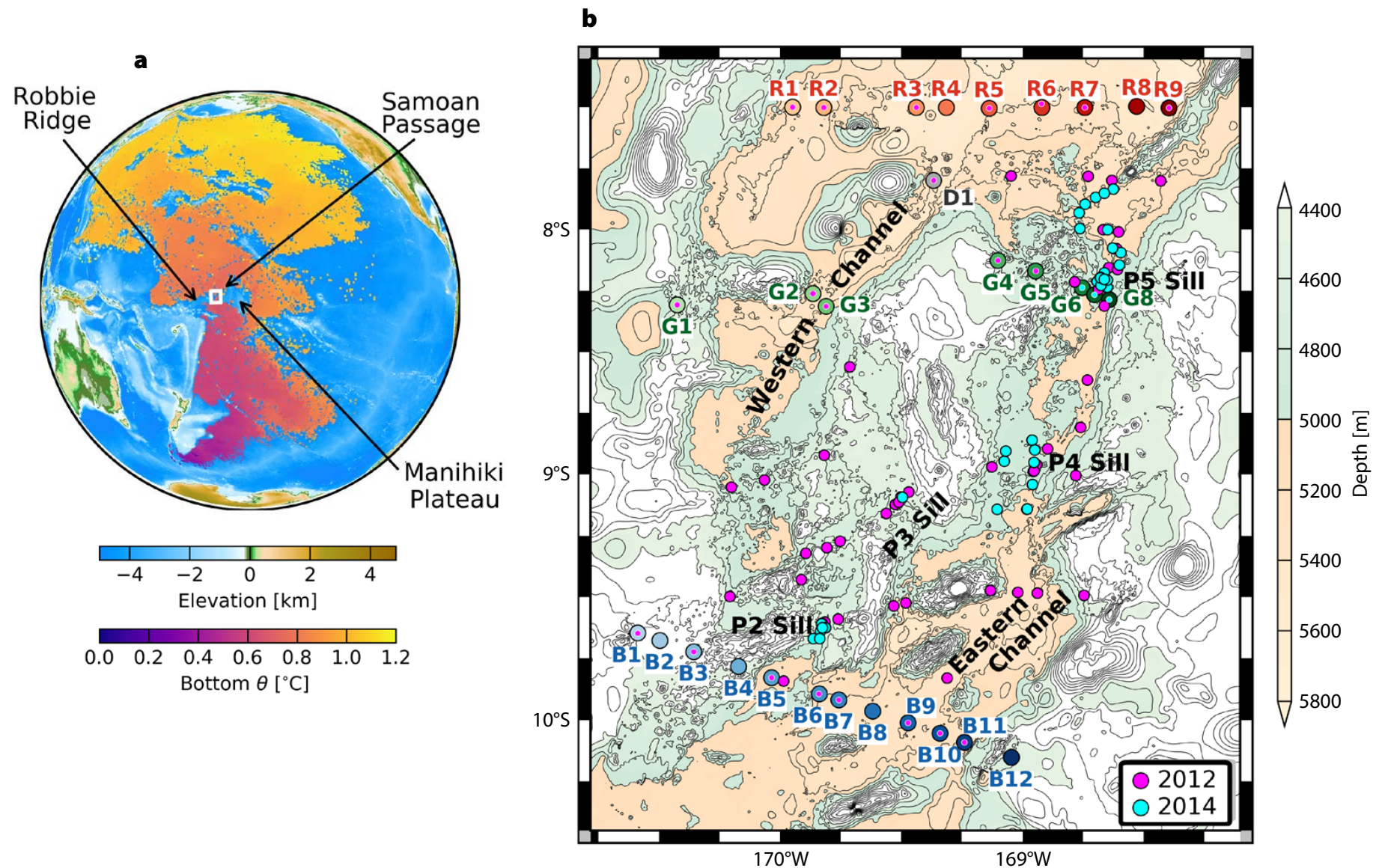

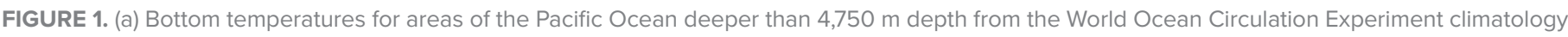

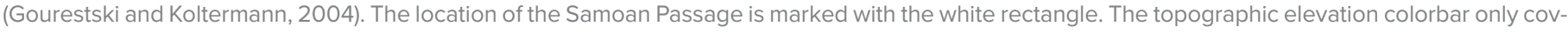

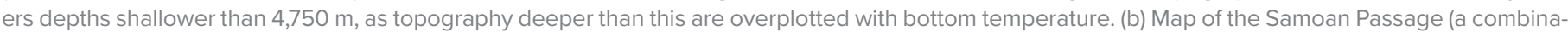

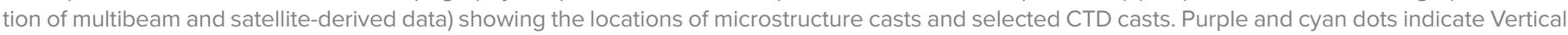

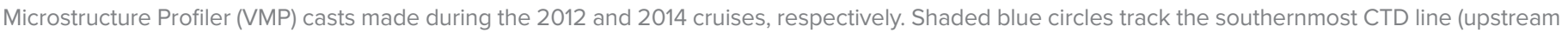

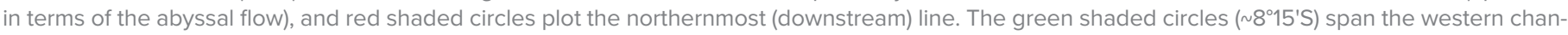

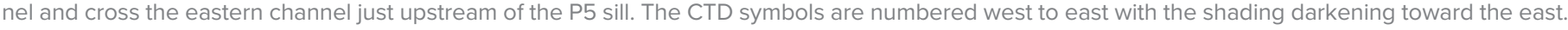

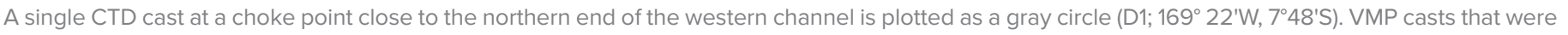
taken concurrently with the CTD casts are shown overplotted with smaller diameter dots. The bathymetry contour line interval is 200 m. 
cal Nasmyth spectrum (Oakey, 1982) was used to account for missing variance in the observed spectra. Dissipation rates are nominally log-normally distributed, and a factor of two is considered to the approximate uncertainty in $\varepsilon$ measurements (Moum et al., 1995).

Figure 1b shows Samoan Passage bathymetry. Voet et al. (2015) found that the abyssal flow in the passage is divided between two channels: the deeper eastern channel through which the majority of the coldest water flows, and a more convoluted western channel. The highresolution multibeam bathymetry shows a large number of abyssal hills and other small-scale bathymetric features. The purple dots mark the locations of VMP casts during the 2012 cruise that covered both the eastern and western channels, including survey lines assumed to be representative of the upstream and downstream abyssal water masses (here, we define upstream and downstream directions in terms of the abyssal flow, so downstream is toward the northern end of the passage). As the focus was on transport pathways, casts generally targeted the gaps between abyssal hills. The cyan dots show the locations of VMP casts during the 2014 cruise, which are clustered around three sills: one that controls the flow into the western channel (P2) and two that are located within the eastern channel (P4 and P5). The majority of the $2014 \mathrm{VMP}$ casts are at or downstream of the northern (P5) sill, which Alford et al. (2013) identified as the location where most of the water mass modification occurs. Larger circles show the locations of 30 CTD/LADCP, with colocated VMP casts represented by overplotted small dots.

\section{MIXING}

\section{Water Mass Change Along the Samoan Passage}

The bottom water of Antarctic origin enters the southern end of the passage as a nearly homogeneous layer (Figure 2a). We found the coldest water to be $\Theta_{\text {min }}=0.663^{\circ} \mathrm{C}\left(\sigma_{4_{\text {max }}}=45.986 \mathrm{~kg} \mathrm{~m}^{-3}\right)$ within a $400 \mathrm{~m}$ thick layer colder than $\Theta=0.670^{\circ} \mathrm{C}$. Starting around $\Theta=0.7^{\circ} \mathrm{C}$ $(\sim 4,600 \mathrm{~m}$ depth), there was an interface with an increased vertical gradient of $0.5^{\circ} \mathrm{C}\left(\sim 0.08 \mathrm{~kg} \mathrm{~m}^{-3}\right)$ over $500-600 \mathrm{~m}$. By the time the water exited the passage, this cold water layer had been eroded away, and the near bottom stratification had increased (Figure 2c). Although the northern section is several hundred meters deeper, the coldest water measured there was only $\Theta_{\min }=0.719^{\circ} \mathrm{C}$ $\left(\sigma_{4_{\text {max }}}=45.976 \mathrm{~kg} \mathrm{~m}^{-3}\right)$, which represents an approximately 55 millidegree Celsius increase in temperature, or a $0.010 \mathrm{~kg} \mathrm{~m}^{-3}$ decrease in density, as the abyssal layer transits the $250 \mathrm{~km}$ long passage.

Figure $2 \mathrm{~b}$ shows the conservative temperature profiles across the western and eastern channels at $\sim 8^{\circ} 15^{\prime} \mathrm{S}$ (green dots in Figure $1 \mathrm{~b})$. The three eastern-most pro- files (G6-G8) are just upstream (south) of the P5 sill. At this location, the thickness of the nearly homogeneous layer below the interface was similar to that observed at the southern line, although it had warmed slightly $\left(\Theta_{\min }=0.681^{\circ} \mathrm{C}\right)$ and the interface had sharpened considerably to as much as $0.25^{\circ} \mathrm{C}$ in $50 \mathrm{~m}$. The two stations between the eastern and western passages (G4 and G5) had sharp interfaces similar to those in the eastern channel, but the casts were shallower $(4,432 \mathrm{~m}$ and 4,682 $\mathrm{m}$, respectively) and registered slightly warmer bottom temperatures $\left(0.753^{\circ} \mathrm{C}\right.$ and $0.716^{\circ} \mathrm{C}$, respectively). The stations in the western channel (G1-G3) showed a weaker interface $\left(\sim 0.3^{\circ} \mathrm{C}\right.$ over $500 \mathrm{~m}$ ) and $\Theta_{\min } \approx 0.76^{\circ} \mathrm{C}$.

At the entrance to the Samoan Passage, the depth of the interface shallowed toward the west (Figure 2a), consistent with a northward geostrophic flow of this layer. The depth of the $\Theta=0.9^{\circ} \mathrm{C}$ interface decreased from $4,058 \mathrm{~m}$ at location B1 to $4,315 \mathrm{~m}$ at B12 (262 km away). At $\sim 8^{\circ} 15^{\prime} \mathrm{S}$ (Figure $2 \mathrm{~b}$ ), the lateral gradient of the interface in the eastern channel had steepened such that at $\Theta=0.9^{\circ} \mathrm{C}$ the interface on the eastern side of the channel (G8) was $180 \mathrm{~m}$ deeper than $13.5 \mathrm{~km}$ to the west (G6). Profiles G6 and G8 were taken $\sim 12$ hours apart and therefore at the same phase of the semidiurnal tide. Cusack et al. (2019) found that tides only played a minor role in flow modulation and mixing at a mooring located between
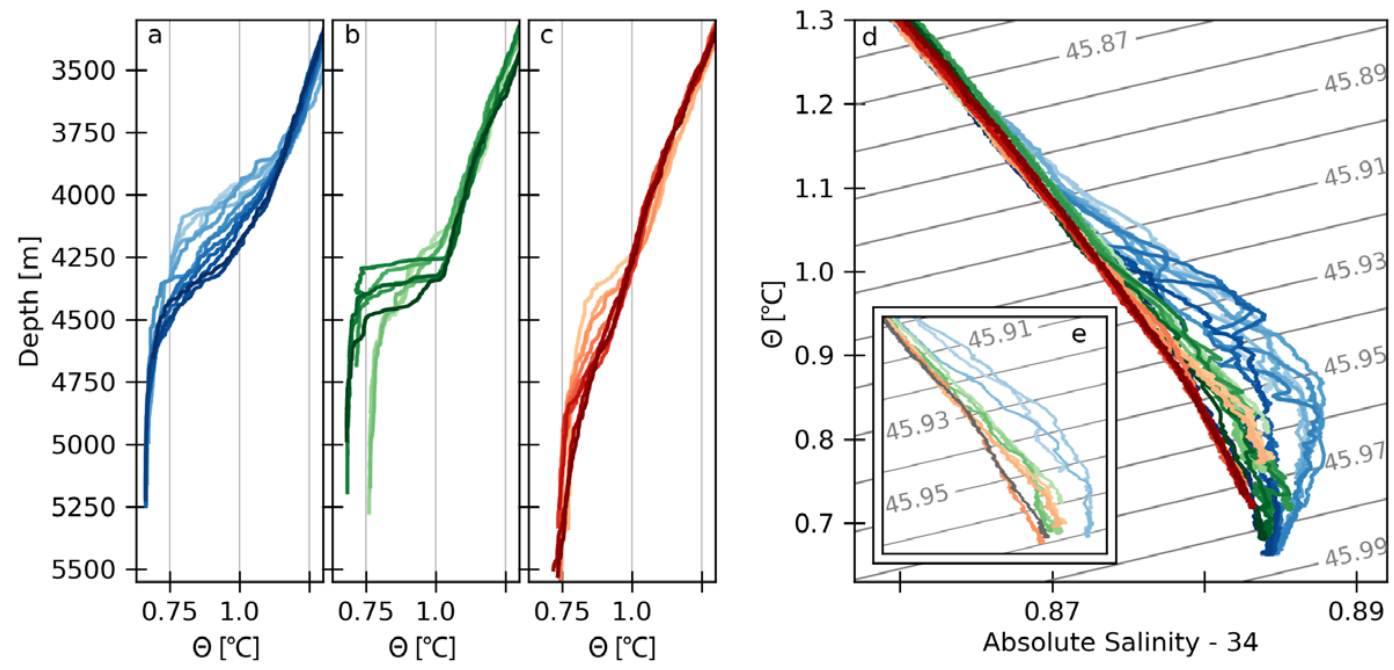

FIGURE 2. $(a-c)$ Conservative temperature $(\Theta)$ versus depth from CTD casts for three sections. Colors correspond to profile locations in Figure $1 \mathrm{~b}$, with darker line shading for profiles toward the east. (d) Temperature-salinity (TS) diagram for all three sections. $\sigma_{4}$ contours are shown. (e) Zoom of TS diagram showing the three westernmost CTD casts on the southern (B1-B3), central (G1$\mathrm{G} 3)$, and the northern (R1-R3) lines, as well as the profile near the northern end of the western channel (D1; gray line). 
profiles G6 and G8.

A temperature-salinity (TS) diagram (Figure 2d) shows that much of the eastwest variation in water properties below 3,500 $\mathrm{m}$ depth had been erased over the length of the passage. With the exception of the two westernmost profiles (R1, R2), the TS data from the northern line collapsed onto a single curve. At the entrance to the passage, there was a salinity maximum within the interface that increased in strength toward the west. This salinity signature corresponds to remnant North Atlantic Deep Water (Alford et al., 2013; Voet et al., 2015). The majority of the salinity anomaly had been mixed away by $\sim 8^{\circ} 15^{\prime} \mathrm{S}$ (green dots), which is still upstream of the P5 sill where largest changes in temperature occurred.

That the two westernmost profiles on the northern CTD line (R1, R2) do not collapse onto the same TS curve as the rest of the water exiting the passage is worth further investigation. Figure $2 \mathrm{e}$ shows the observed TS curves for the three western profiles in each CTD line. The water mass properties at G1-G3 $\left(8^{\circ} 15^{\prime} \mathrm{S}\right)$ are close to those observed at R1 and R2, but noticeably different from the remaining downstream observations

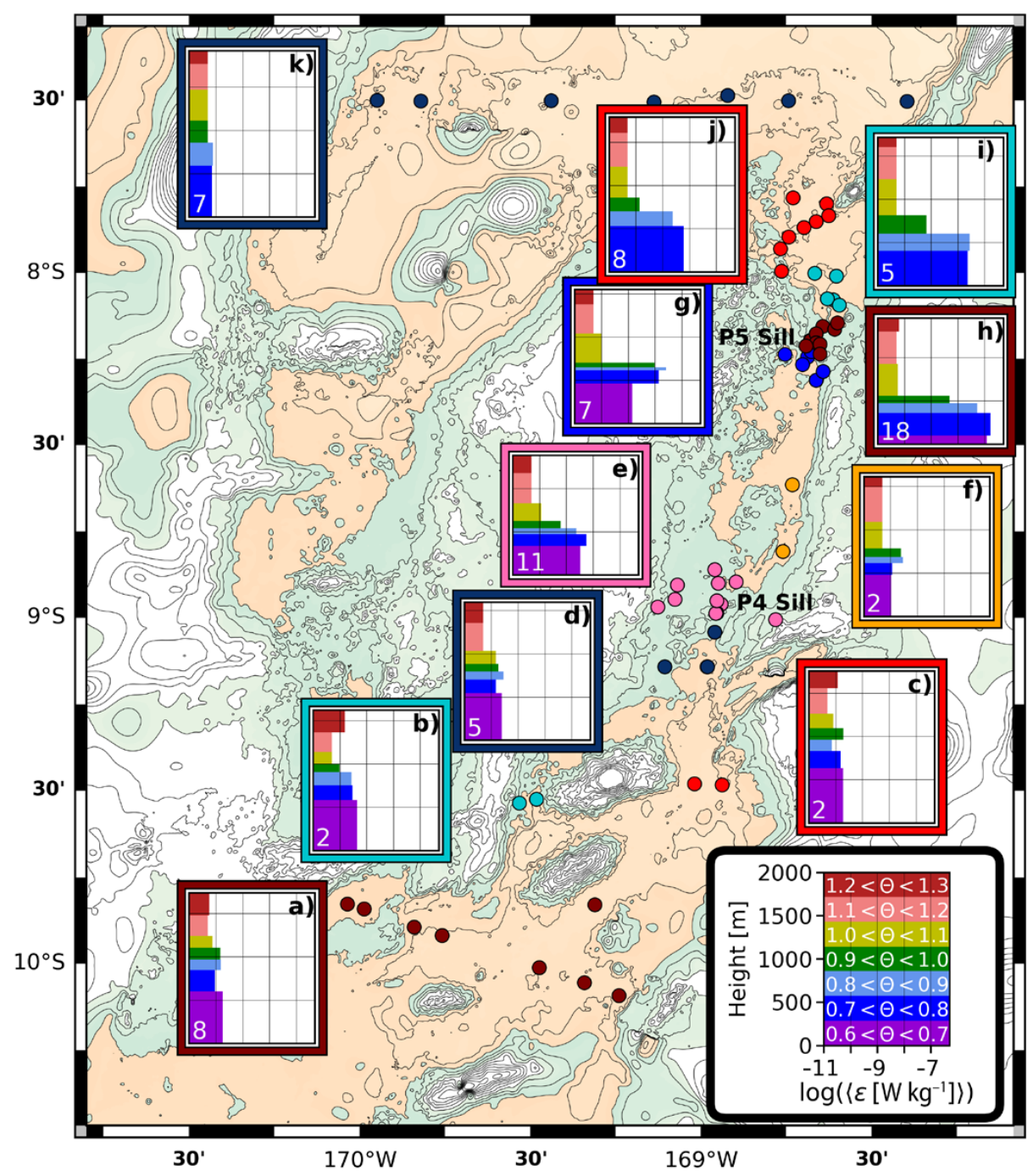

FIGURE 3. Turbulent kinetic energy dissipation rate $(\varepsilon)$ in the eastern channel. The observations are averaged into groups with similar geographic and flow characteristics. The horizontal extents of the bars, which are color-coded by $\Theta$ class, gives the average $\varepsilon$, and the vertical extent is the average thickness of that temperature class. The white numbers in the lower-left corners of each group give the number of microstructure profiles. Horizontal grid lines are every $500 \mathrm{~m}$, and vertical grid lines for $\varepsilon$ are spaced an order of magnitude apart-see key in lower-right corner. The underlying bathymetry map has the same colormap and contour interval as Figure 1b. (represented by R3). The observations at D1 (gray line, located at $7^{\circ} 48^{\prime} \mathrm{S}, 169^{\circ} 22^{\prime} \mathrm{W}$, where the western channel starts to open out onto a wider plain) have essentially the same TS structure as R3 and hence the rest of the northern line. This implies that, if the water reaching R1 and R2 came through the Samoan Passage, it could not flow through the western channel much further north of $\sim 8^{\circ} 15^{\prime} \mathrm{S}$ where it would undergo significant water mass modification. Figure $1 \mathrm{~b}$ shows a relatively flat basin south of R1 that may be a low mixing flow pathway; however, the bathymetry in that area is satellite derived (STRM30; Becker et al., 2009), so the actual smallscale roughness is underrepresented. Voet et al. (2015) observed that the transport per unit width at the southern end of this basin (G1) was small and southward, suggesting the flow needed to branch off north of G2. From our observations, it is not possible to confidently determine the flow pathway to R1 and R2.

\section{Spatial Mixing Patterns Within \\ the Samoan Passage}

To illustrate the spatial mixing patterns in the Samoan Passage, the microstructure data were grouped by geographic and flow characteristics and averaged into conservative temperature classes:

$$
\begin{aligned}
& \cdot 0.6^{\circ} \leq \Theta<0.7^{\circ} \mathrm{C}, \\
& \cdot 0.7^{\circ} \leq \Theta<0.8^{\circ} \mathrm{C}, \\
& \cdot 0.8^{\circ} \leq \Theta<0.9^{\circ} \mathrm{C}, \\
& \cdot 0.9^{\circ} \leq \Theta<1.0^{\circ} \mathrm{C}, \\
& \cdot 1.0^{\circ} \leq \Theta<1.1^{\circ} \mathrm{C}, \\
& \cdot 1.1^{\circ} \leq \Theta<1.2^{\circ} \mathrm{C}, \\
& \cdot 1.2^{\circ} \leq \Theta<1.3^{\circ} \mathrm{C} .
\end{aligned}
$$

These nominally correspond to density anomaly classes:

- $45.993 \lesssim \sigma_{4} \lesssim 45.976 \mathrm{~kg} \mathrm{~m}^{-3}$,

- $45.976 \lesssim \sigma_{4} \lesssim 45.958 \mathrm{~kg} \mathrm{~m}^{-3}$,

- $45.958 \lesssim \sigma_{4} \lesssim 45.941 \mathrm{~kg} \mathrm{~m}^{-3}$,

- $45.941 \lesssim \sigma_{4} \lesssim 45.923 \mathrm{~kg} \mathrm{~m}^{-3}$,

- $45.923 \lesssim \sigma_{4} \lesssim 45.905 \mathrm{~kg} \mathrm{~m}^{-3}$,

- $45.905 \lesssim \sigma_{4} \lesssim 45.887 \mathrm{~kg} \mathrm{~m}^{-3}$,

- $45.887 \lesssim \sigma_{4} \lesssim 45.869 \mathrm{~kg} \mathrm{~m}^{-3}$, respectively. In Figures 3 and 5, the horizontal extents of the bars, which are colorcoded by $\Theta$ class, give the average dissipation rate, and the vertical extents give 
the average thickness of that temperature class. Consequently, the area of a bar is related to the integral value of $\varepsilon$ in the temperature class. The locations of the VMP casts in each group are shown by the dots of the same color as the inset border.

Figure 3 plots the turbulent kinetic energy dissipation rate for groups of profiles in the eastern channel. Cusack et al. (2019) propose a framework for characterizing flow and mixing over a sill, which, although the eastern channel contains two major sills, is useful for describing the channel as a whole. Their framework consists of three regimes: (1) upstream of the sill is characterized by weak mixing and weak flow within a thicker layer below the interface; (2) close to the sill, the layer thickness is a minimum, the flow is fast, and high mixing values are concentrated in the interface; and (3) downstream of the sill, the mixing remains large and is distributed throughout the layer.

At the entrance to the eastern channel, the coldest layer $\left(\Theta<0.7^{\circ} \mathrm{C}\right)$ had an average thickness of $\sim 600 \mathrm{~m}$ (Figure $3 \mathrm{a}$ ), which was maintained until the P4 sill (Figure 3b-d). The average dissipation rates in this region of the channel are less than $5 \times 10^{-10} \mathrm{~W} \mathrm{~kg}^{-1}$ in all $\Theta$ classes. This section of the channel is best described by Cusack et al.s first regime.

Figure 3e shows that at the $\mathrm{P} 4$ sill, the $\Theta<0.7^{\circ} \mathrm{C}$ layer thinned by $\sim 200 \mathrm{~m}$ with a corresponding increase in $\varepsilon$ to over $2 \times 10^{-9} \mathrm{~W} \mathrm{~kg}^{-1}$. Downstream of the sill, the thickness of the $\Theta<0.7^{\circ} \mathrm{C}$ layer rebounded to $\sim 500 \mathrm{~m}$ and $\varepsilon$ returned to $10^{-10} \mathrm{~W} \mathrm{~kg}^{-1}$ (Figure 3f). This sill does not neatly fit into any of Cusack et al's regimes. We argue against the second regime as the dissipation rate was not substantially elevated compared to the coldest layer $\left(\varepsilon\right.$ in the $0.7 \leq \Theta<0.8^{\circ} \mathrm{C}$ layer was only a factor of two larger), and $\varepsilon$ values below the interface were not elevated downstream compared to upstream (Figure $3 \mathrm{f}$ versus $3 \mathrm{~d}$ ). A possible explanation for this is that the hydraulic control of the transport over the P5 sill downstream maintains a sufficiently deep bottom layer that a hydrau- lic control point never forms at the P4 sill. Theoretical and laboratory work by Pratt (1984) suggested that it is usually the downstream obstacle that controls the flow, even when the upstream obstacle is slightly higher than the downstream one. Sánchez-Garrido et al. (2011) found that the Tangier Basin, between the two main sills in the Strait of Gibraltar, had a mode-2 baroclinic hydraulic control (where the layer interface displacements are in counterphase). Figure 4 provides evidence of a possible mode- 2 control at the P4 sill: downstream of the sill, the $\Theta=0.7^{\circ} \mathrm{C}$ isotherm descends, whereas the $\Theta=0.8^{\circ} \mathrm{C}$ isotherm ascends. This spreading of the isotherms is not the isolated, homogeneous, and relatively stagnant wedge often associated with mode-1 hydraulic flows (e.g., Pawlak and Armi, 1997; Winters, 2016), as the horizontal velocities within are similar to those in the bottom layer and it remains stratified. Further information about the nature of the hydraulic control at the P4 sill can be gained by fitting the observed velocity and stratification to a 2.5-layer model (Sánchez-Garrido et al., 2011), where water with $\Theta<0.7^{\circ} \mathrm{C}$ constitutes the lowest layer (layer 3 ), water with $0.7^{\circ} \mathrm{C}<\Theta<1.0^{\circ} \mathrm{C}$ makes up the mid- dle layer, and warmer water makes up an infinitely deep and quiescent overlying layer. As shown by Sánchez-Garrido et al. (2011), the displacements $\eta_{1}$ and $\eta_{2}$ of the upper and lower interfaces $\left(1.0^{\circ} \mathrm{C}\right.$ and $0.7^{\circ} \mathrm{C}$ surfaces) due to the presence of the wave that is arrested at the section of critical control indicate whether the control is first mode $\left(\eta_{1} \eta_{2}>0\right)$ or second mode $\left(\eta_{1} \eta_{2}<0\right)$. They further show that $\eta_{2}=\alpha \eta_{1}$, where

$$
\alpha=\frac{\left(F_{2}^{2}-r /(1-r)\right)}{F_{2}^{2}}
$$

and $F_{2}^{2}=U_{2}^{2} /\left(g_{32}^{\prime} D_{2}\right), g_{32}^{\prime}=g\left(\rho_{3}-\rho_{2}\right) / \rho_{3}$, $r=\left(\rho_{2}-\rho_{1}\right) /\left(\rho_{3}-\rho_{1}\right)$, and $D_{n}, U_{n}$, and $\rho_{n}$, are the depth and vertically averaged velocity and density in layer $n$. Nominal values based on data taken near the crest of the P4 sill are $0.12<U_{2}<0.2 \mathrm{~m} \mathrm{~s}^{-1}$ and $r=0.7$, which gives $-16.1<\alpha<-5.4$. Thus, a rise in the level of the upper interface corresponds to a much larger drop in the level of the lower interface, indicating a mode- 2 control. This suggests that in the Samoan Passage the P5 sill would be the controlling sill for the overflow as a whole (mode- 1 control), while the $\mathrm{P} 4$ sill would be the controlling sill for some colder, lower sublayer of the flow.

The P5 sill (Figure 3g) is hydraulically
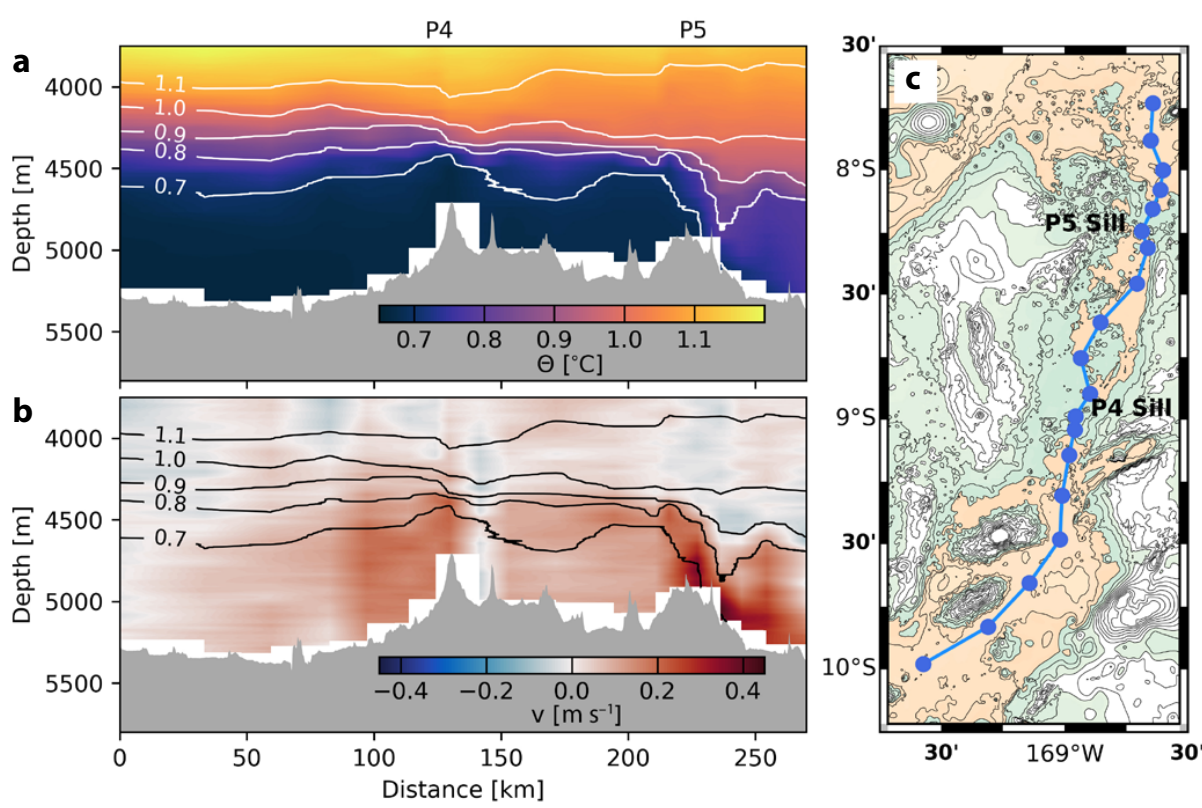

FIGURE 4. (a) Conservative temperature ( $\Theta$ ) section along the eastern channel. (b) North-south velocity $(v)$ section along the eastern channel. (c) Map showing the locations of the CTD casts. The underlying bathymetry map has the same colormap and contour interval as Figure $1 \mathrm{~b}$. 
controlled (Alford et al., 2013), and corresponds to Cusack et al's second regime. The dissipation rate for $0.7^{\circ} \leq \Theta<1.0^{\circ} \mathrm{C}$ was an order of magnitude higher than in the $450 \mathrm{~m}$ thick bottom layer, and the velocity in the bottom layer reaches $\sim 0.4 \mathrm{~m} \mathrm{~s}^{-1}$ (Figure $4 b$ ). Figure $2 \mathrm{~b}$ shows that the interface in this part of the channel was best represented by the $0.8^{\circ} \leq \Theta<0.9^{\circ} \mathrm{C}$ layer, which had the highest dissipation rate $\left(\varepsilon=2.5 \times 10^{-8} \mathrm{~W} \mathrm{~kg}^{-1}\right)$ and an average thickness of only $33 \mathrm{~m}$. Downstream (Figure 3h), the thickness of the $\Theta<0.7^{\circ} \mathrm{C}$ layer had decreased to $100 \mathrm{~m}$, whereas the $0.8^{\circ} \leq \Theta<0.9^{\circ} \mathrm{C}$ layer thickness more than trebled. The average $\mathcal{E}$ in waters colder than $\Theta=0.9^{\circ} \mathrm{C}$ was greater than $5 \times 10^{-8} \mathrm{~W} \mathrm{~kg}^{-1}$. High turbulence was found throughout this $20 \mathrm{~km}$ long region and not just immediately downstream of the sill (see the high-resolution towed CTD/LADCP section presented by Alford et al., 2013). Mixing with the overlying water completely erodes the $\Theta<0.7^{\circ} \mathrm{C}$ layer (no water colder than $\Theta=0.7^{\circ} \mathrm{C}$ was observed downstream of this section). The Figure $3 i$ and $3 j$ panels are best described as fitting Cusack et al's third regime. The mixing was more moderate and confined to the thick bottom layer, albeit that layer is now $0.7^{\circ} \leq \Theta<0.8^{\circ} \mathrm{C}$. The northernmost group (Figure $3 \mathrm{k}$ ) exhibited weak mixing $\left(<10^{-10} \mathrm{~W} \mathrm{~kg}^{-1}\right)$ throughout the abyssal water column.

Figure 5 summarizes the dissipation rates observed in the western channel. As noted by Voet et al. (2015), no water with $\Theta<0.7^{\circ} \mathrm{C}$ is found in this channel, in large

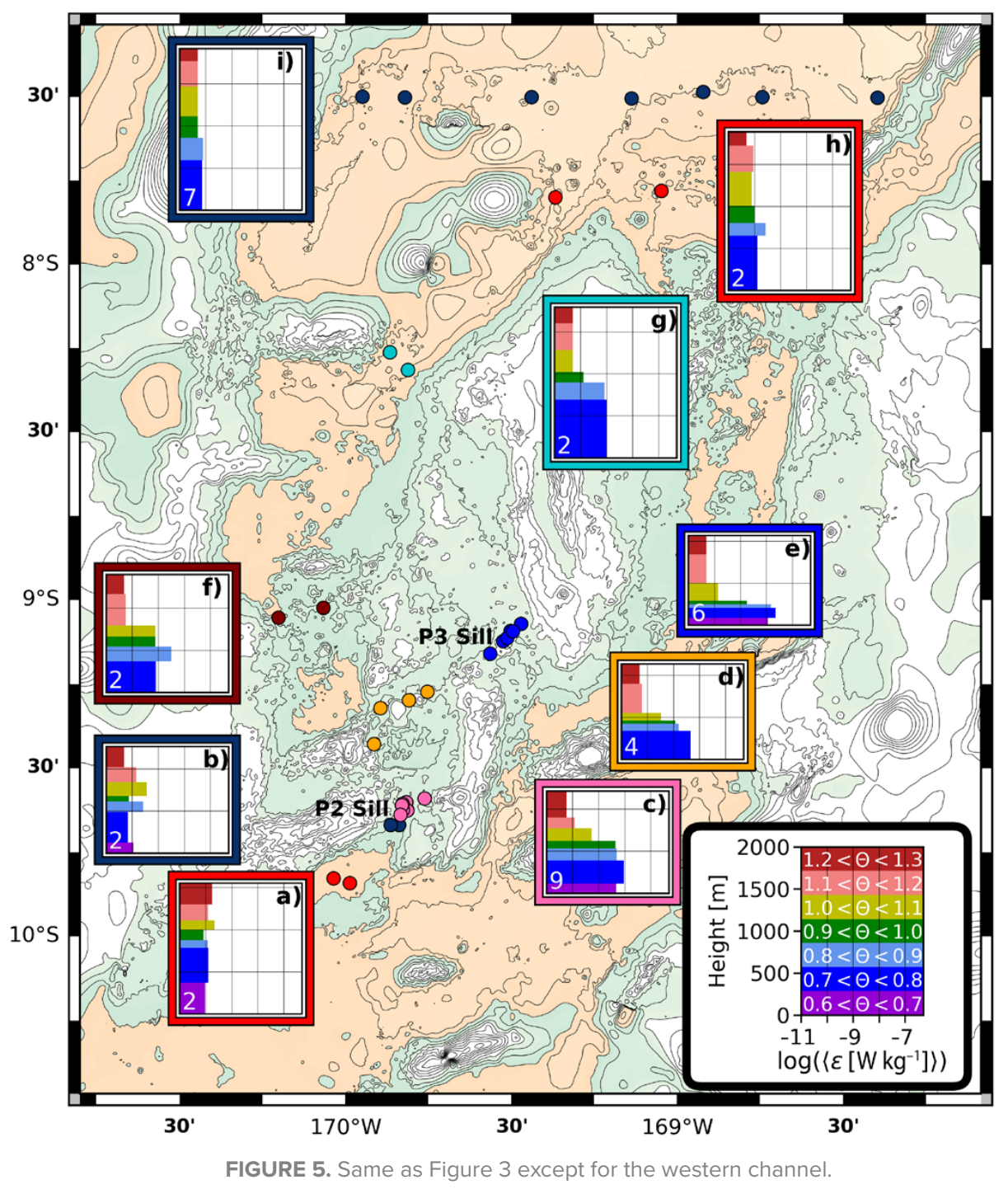

part due to blocking at the two entrance sills (P2 and P3), although mixing at these sills also plays a role. Figure 5 a shows a subsection of the southern line, which, due to the topographic ridge east of the $\mathrm{P} 2$ sill, is, presumably, the location through which most of the water approaching the $\mathrm{P} 2$ sill flows. The $\Theta<0.7^{\circ} \mathrm{C}$ layer was thinner here than in Figure 3a because of the shallower bottom depth. As Figure 2a shows, the interface depth was shallower on this side of the channel due to the geostrophic flow of the deep western boundary current. Immediately upstream of the P2 sill (Figure 5b), $\varepsilon$ values remain at background levels throughout the abyssal water column. The thickness of the $\Theta<0.7^{\circ} \mathrm{C}$ layer was further reduced by the shallowing bottom topography.

The $\Theta<0.7^{\circ} \mathrm{C}$ layer was mixed away over the P2 sill, requiring a temperature increase of over 30 millidegrees Celsius. The average dissipation rates for $\Theta$ layers colder than $1.0^{\circ} \mathrm{C}$ were essentially constant with depth, with a range of $5 \times 10^{-9}<\varepsilon<1 \times 10^{-8} \mathrm{~W} \mathrm{~kg}^{-1}$ (Figure 5c). Like the P4 sill (Figure 3e), the spatial average at the $\mathrm{P} 2$ sill does not show clear evidence of interfacial mixing. However due to complex topography on the sill crest, the mixing varied over short spatial scales along and across the sill. Cusack et al. (2019) found interfacial mixing at a long-term mooring located on the sill crest, but none of the VMP casts showed interfacial mixing (including those approximately $2 \mathrm{~km}$ away from the mooring; Figure 7a). Two along-channel towed CTD/LADCP sections showed higher dissipation rates behind an approximately $200 \mathrm{~m}$ high bump on the western end of the sill crest compared to the flatter eastern section (Alford et al., 2013). The VMP profiles did not show an obvious east-west trend. Downstream of the P2 sill (Figure $5 \mathrm{~d}$ ), the coldest layer, now $0.7^{\circ} \leq \Theta<0.8^{\circ} \mathrm{C}$, thickens but remains nearly as turbulent.

The other entrance sill (P3; Figure 5e) showed similar patterns to the P2 sill, albeit with thinner layer heights and slightly higher dissipation rates 
$\left(1-2 \times 10^{-8} \mathrm{~W} \mathrm{~kg}^{-1}\right)$. Figure $5 \mathrm{f}$ and $5 \mathrm{~g}$ panels, located downstream of both entrance sills, show that the thickness of the $0.7^{\circ} \leq \Theta<0.8^{\circ} \mathrm{C}$ layer increased primarily due to the deeper bottom depth. By the exit of the western channel (Figure 5h), the abyssal dissipation rates had returned to background levels $\left(\sim 10^{-10} \mathrm{~W} \mathrm{~kg}^{-1}\right)$. This is in agreement with the earlier discussion that there is very little water mass change between here and the northernmost line (Figure 5i).

The mixing of density across isopycnal surfaces, diapycnal diffusivity, is calculated as

$$
K_{\rho}=\Gamma \frac{\varepsilon}{N^{2}},
$$

where $\Gamma$ is an eddy or flux coefficient, and $N^{2}=-g / \rho_{0}(\partial \rho / \partial z)$. Osborn (1980) proposed $\Gamma \leq 0.2$. Taking the upper bound, $\Gamma=0.2$, is a common approach in the literature (e.g., Polzin et al., 1997; Lavelle et al., 2004; Kunze et al., 2006; Waterhouse et al., 2014; Gregg et al., 2018) and the one used in this work. Overall, the patterns are very similar to those for $\varepsilon$ except the weaker stratification in the coldest layers tends to increase the mixing in that layer compared to the overlying layers (Figure 6). At the P3 (Figure 6b) and P5 (Figure 6e) sills, the diapycnal diffusivity exceeds $10^{-2} \mathrm{~m}^{2} \mathrm{~s}^{-1}$, similar to the average values over the Camarinal Sill in the Strait of Gibraltar (Wesson and Gregg, 1994; Gregg, 2004).

\section{DISCUSSION}

Turbulent mixing can be highly intermittent. For example, Alford et al. (2011) analyzed a two and a half year abyssal mooring record north of Hawai' $i$ and found a single mixing event dominated the record. So, the obvious and important question that arises when a mixing geography is derived from a limited number of microstructure observations is, How representative is it? Or, equivalently, Would temporal variability change the patterns significantly?

Cusack et al. (2019) used overturns to examine the temporal variability of dissipation rates in two long-term (500-day) and 16 short-term (4- to 27-day) moored records collected as part of this experiment. Overturning patches were detected in $97 \%$ of profiles (\# profiles $=698$ ) from the long-term mooring at the P2 sill. A quantitative scale for the size of an overturn is given by the Thorpe scale (Thorpe, 1977; Dillon, 1982), which is the rootmean-square of the distance water parcels within an overturn must be displaced to achieve a statically stable density profile. Dissipation rates are then estimated by comparing the Thorpe scale with the Ozmidov scale $\left(L_{O}=\left(\varepsilon / N^{2}\right)^{1 / 2}\right)$, which represents the largest eddy unaffected by buoyancy. Cusack et al. (2019) concluded that dissipation rates throughout the Samoan Passage were persistent. For each of the 18-month moorings, the uncertainties $\left(10^{\text {th }}\right.$ to $90^{\text {th }}$ percentiles $)$ in the time mean of the depth integrated dissipations was about one order of magnitude. Although tides and near-inertial waves were observed at some of these moorings, their effect on mixing levels was found to be small.

Here, we present three examples to show that the dissipation rates in the Samoan Passage are relatively consistent over both long and short timescales. Figure 7a shows considerable similarities between three microstructure dissipation profiles from the same location atop the P2 sill. Two profiles were measured three weeks apart during the 2012 cruise, and the third was taken in 2014 . In all three profiles, the $0.7^{\circ} \leq \Theta<0.8^{\circ} \mathrm{C}$ and $0.8^{\circ} \leq \Theta<0.9^{\circ} \mathrm{C}$ temperature classes have similar thicknesses and $\varepsilon$ exceeds $10^{-8} \mathrm{~W} \mathrm{~kg}^{-1}$. There are some differences, most noticeably that the dissipation rate for $\Theta<0.7^{\circ} \mathrm{C}$ was two to three orders of magnitude less during the January 2014 profile.

During the 2014 cruise, a 36-hour (eight VMP profile) time series was conducted near the hydraulic jump immediately downstream of the P5 sill (white vertical lines in Figure 7c). Again, at first order, temporal variability does not change the overall depth structure and magnitude of the observed dissipation rates (Figure 7b). The bottom 200-300 $\mathrm{m}$ of all profiles have $\varepsilon$ of

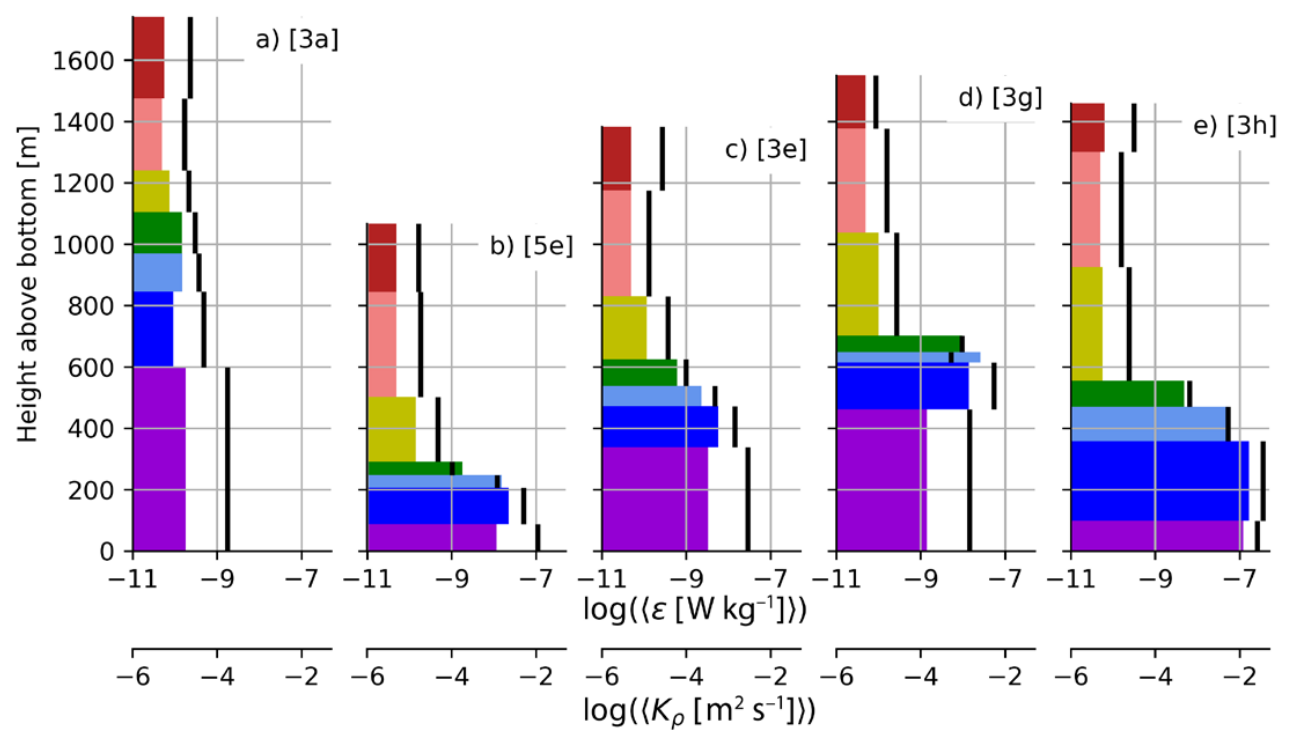

FIGURE 6. Comparison of turbulent kinetic energy dissipation $(\varepsilon)$ with diapycnal diffusivity $\left(K_{\rho}\right)$ as a function of $\Theta$ class for selected geographic groupings. Horizontal bars in each panel colored according to $\Theta$ class show the average $\varepsilon$ and layer thickness (i.e., same as the panels in Figures 3 and 5). Vertical black lines give the average $K_{\rho}$ in each $\Theta$ layer. The number is square brackets in the upper-right corner of each panel corresponds to a panel in either Figure 3 or Figure 5. (a) Entrance to the eastern channel. (b) P3 sill. (c) P4 sill. (d) P5 sill. (e) Immediately downstream of the P5 sill. 
a)

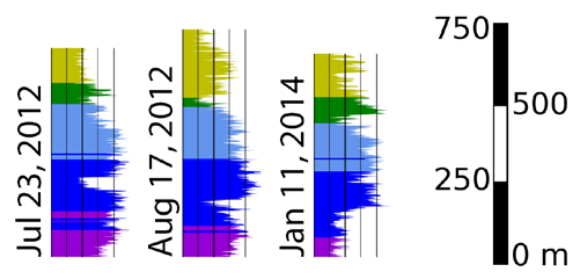

b)

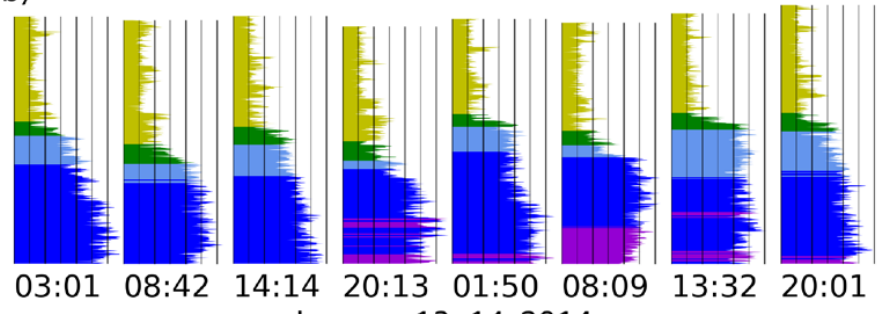

January 13-14, 2014
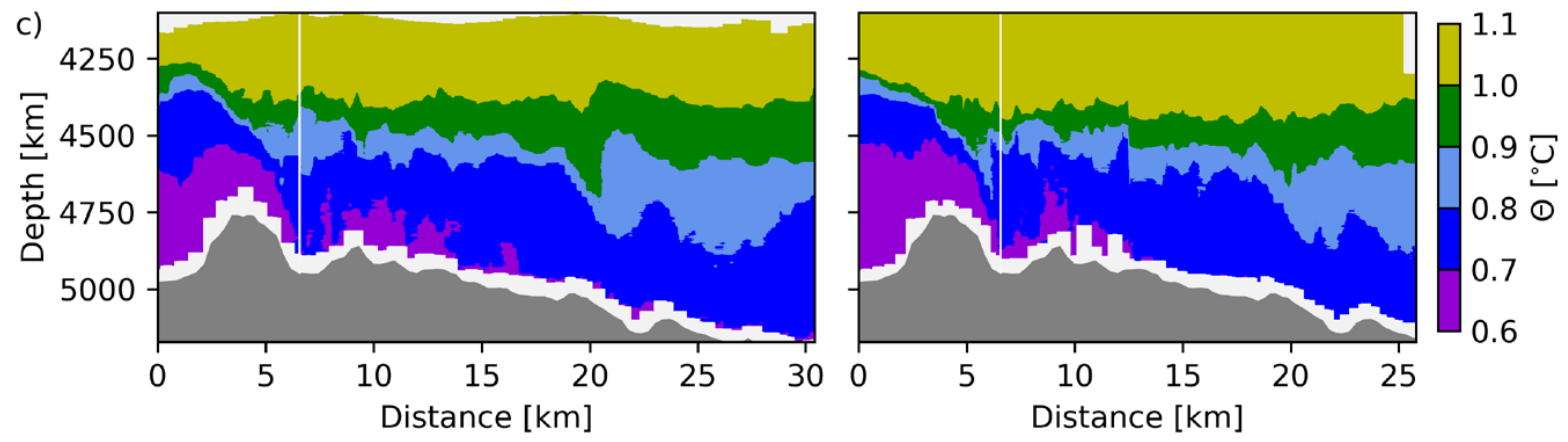

FIGURE 7. (a) Microstructure dissipation profiles from the same location on top of the P2 sill. The $\Theta$ color-coding matches discrete temperature classes used in Figures 3 and 5 and the color bar in panel c. The horizontal axis is turbulent kinetic energy dissipation rate with the vertical lines spaced a decade apart starting at $\varepsilon=10^{-12} \mathrm{~W} \mathrm{~kg}^{-1}$. The darker vertical lines are every two decades. The vertical scale is the height of the water column colder than $\Theta=1.1^{\circ} \mathrm{C}$. (b) Dissipation profiles from a 36-hour time series collected just downstream of the P5 sill (white lines in panel c). (c) Two along channel towed CTD/LADCP sections taken 17 months apart. See Alford et al. (2013) for details of track location. The left panel plots observations from the 2012 cruise and the right panel from the 2014 cruise. In the 2014 tow-yo, the CTD/LADCP package was briefly recovered, which resulted in the jump in the isotherm depths at $x=12.5 \mathrm{~km}$.

$\sim 10^{-7} \mathrm{~W} \mathrm{~kg} \mathrm{~kg}^{-1}$ Depth-integrated dissipation rates for $\Theta<0.9^{\circ} \mathrm{C}$ vary between $1.6 \times 10^{-2} \mathrm{~W} \mathrm{~m}^{2}$ and $2.1 \times 10^{-1} \mathrm{~W} \mathrm{~m}^{2}$. Although there was a semidiurnal variation in the interface height (most easily seen in the position of the $0.9^{\circ} \leq \Theta<1.0^{\circ} \mathrm{C}$ layer), there was no such signal in the depth integrated dissipation rates.

The final example considers the flow conditions driving the mixing. The towed CTD/LADCP section over the P5 sill presented by Alford et al. (2013) was repeated during the 2014 cruise. The second occupation followed the same track but was $5 \mathrm{~km}$ shorter at the northern end. No effort was made to match the phase of the tide between the two tow-yos. Figure 7c compares the conservative temperature in the same $0.1^{\circ} \mathrm{C}$ classes described above in the section on Spatial Mixing Patterns Within the Samoan Passage. Many of the same flow features are obvious in both tow-yo sections. Isotherms plunge hundreds of meters over the downstream flank of the main sill ( $x=\sim 5 \mathrm{~km})$, consistent with the hydraulic control identi- fied by Alford et al. (2013). The height of the $\Theta=0.7^{\circ} \mathrm{C}$ isotherm rebounds around $x=10 \mathrm{~km}$, and by the end of the section, this temperature class had essentially disappeared. At $x=20 \mathrm{~km}$, there was a second persistent hydraulic feature, with the plunging and rebounding isotherms most visible in the $\Theta=0.8^{\circ} \mathrm{C}$ isotherm.

\section{SUMMARY}

As part of an extensive experiment to study abyssal transport and water-mass transformation, the first direct microstructure measurements were made in the Samoan Passage, which forms a critical part of the Pacific Meridional Overturning Circulation. Our observations show that along the flow path, the bottom temperature increased by over 55 millidegrees Celsius, the density decreased by $0.010 \mathrm{~kg} \mathrm{~m}^{-3}$, and the North Atlantic Deep Water salinity anomaly disappeared. Spatial analysis of this survey confirms the existence of multiple mixing hotspots that were not confined just to the four main sills; significant mixing also occurred up to $50 \mathrm{~km}$ downstream of the northern sill in the eastern channel (P5) and throughout the western channel. The details of the turbulent mixing varied between the sills. Only the P5 sill appears to have strong mixing at the interface generally associated with hydraulically controlled flow. In contrast, at the other three sills, turbulence in the coldest layer was essentially as large as that in the interface layers. Dissipation at the P4 sill might be influenced by the downstream hydraulic control at the P5 sill.

Microstructure profiles taken at the same locations show similar dissipation patterns between the 2012 and 2014 cruises, as well as over tidal timescales. This combined with Thorpe scale analysis of moored observations (Cusack et al., 2019) strongly suggests weak temporal variability, and hence that the observed spatial patterns are robust. Despite the temporal consistency, the short lateral scales will make developing a parameterization for the dissipation within the Samoan Passage challenging. @ 


\section{REFERENCES}

Alford, M.H., R. Lukas, B.M. Howe, A. Pickering, and F. Santiago-Mandujano. 2011. Moored observations of episodic abyssal flow and mixing at station ALOHA. Geophysical Research Letters 38, L15606, https://doi.org/10.1029/2011GL048075.

Alford, M.H., J.B. Girton, G. Voet, G.S. Carter, J.B. Mickett, and J. M. Klymak. 2013. Turbulent mixing and hydraulic control of abyssal water in the Samoan Passage. Geophysical Research Letters 40(17):4,668-4,674, https://doi.org/10.1002/ grl.50684.

Becker, J.J., D.T. Sandwell, W.H.F. Smith, J. Braud, B. Binder, J. Depner, D. Fabre, J. Factor, S. Ingalls, S.-H. Kim, and others. 2009. Global bathymetry and elevation data at 30 arc seconds resolution: Srtm30_plus. Marine Geodesy 32(4):355-371, https://doi.org/10.1080/01490410903297766.

Cusack, J.M., G. Voet, M. Alford, J.B. Girton, G.S. Carter, L.J. Pratt, K.A. Pearson-Potts, and S. Tan. 2019. Persistent turbulence in the Samoan Passage. Journal of Physical Oceanography, https://doi.org/10.1175/JPO-D-19-0116.1.

Dillon, T.M. 1982. Vertical overturns: A comparison of Thorpe and Ozmidov length scales. Journal of Geophysical Research 87(C12):9,601-9,613, https://doi.org/10.1029/JC087ic12p09601.

Freeland, H. 2001. Observations of the flow of abyssal water through the Samoa Passage. Journal of Physical Oceanography 31(8):2,273-2,279, https://doi.org/10.1175/1520-0485(2001)031 $<2273$ :OOTFOA $>2.0 . \mathrm{CO} ; 2$

Gourestski, V., and K. Koltermann. 2004. WOCE Global Hydrographic Climatology. Berichte des BSH 35(1-52).

Gregg, M. C. 1999. Uncertainties and limitations in measuring $\varepsilon$ and $X_{T}$. Journal of Atmospheric and Oceanic Technology 16(11):1,483-1,490, https://doi.org/10.1175/1520-0426(1999)016 <1483:UALIMA>2.0.CO;2.

Gregg, M.C. 2004. Small-scale processes in straits. Deep Sea Research Part I/ 51:489-503, https://doi.org/10.1016/j.dsr2.2003.08.003.

Gregg, M.C., E.A. D’Asaro, J.J. Riley, and E. Kunze. 2018. Mixing efficiency in the ocean. Annual Review of Marine Science 10:443-473, https://doi.org/10.1146/ annurev-marine-121916-063643.

Kunze, E., J.F. Dower, I. Beveridge, R. Dewey, and K.P. Barlett. 2006. Observations of biologically generated turbulence in a coastal inlet. Science 313:1,768-1,770, https://doi.org/10.1126/ science.1129378.

Lavelle, J.W., I.D. Lozovatsky, and D.C. Smith IV. 2004. Tidally induced turbulent mixing at Irving Seamount: Modeling and measurements. Geophysical Research Letters 31, L10308, https://doi.org/10.1029/2004GL019706.

McDougall, T.J., and P.M. Baker. 2011. Getting Started with TEOS-10 and the Gibbs Seawater Oceanographic Toolbox. SCOR/IAPSO WG127.

Moum, J.N., M.C. Gregg, R.-C. Lien, and M.E. Carr. 1995. Comparison of turbulence kinetic energy dissipation rate estimates from two ocean microstructure profilers. Journal of Atmospheric and Oceanic Technology 12(4):346-366, https://doi.org/10.1175/ 1520-0426(1995)012<0346: COTKED $>2.0 . \mathrm{CO} \cdot 2$

Oakey, N.S. 1982. Determination of the rate of dissipation of turbulent energy from simultaneous tem perature and velocity shear microstructure measurements. Journal of Physical Oceanography 12:56-271, https://doi.org/10.1175/1520-0485(1982) 012<0256:DOTROD>2.0.CO;2.

Osborn, T.R. 1980. Estimates of the local rate of vertical diffusion from dissipation measurements. Journal of Physical Oceanography 10:83-89, https://doi.org/10.1175/1520-0485(1980)010 $<0083$ :EOTLRO>2.0.CO:2.

Osborn, T.R., and W.R. Crawford. 1980. An airfoil probe for measuring turbulent velocity fluctuations in water. Chapter 19 in Air-Sea Interaction: Instruments and Methods. F. Dobson, L. Hasse, and R. Davis, eds, Plenum Press.
Pawlak, G., and L. Armi. 1997. Hydraulics of twolayer arrested wedge flows. Journal of Hydraulic Research 35(5):603-618, https://doi.org/10.1080/ 00221689709498397.

Peters, H., M.C. Gregg, and J.M. Toole. 1988. On the parameterization of equatorial turbulence. Journa of Geophysical Research 93(C2):1,199-1,218, https://doi.org/10.1029/JC093iC02p01199.

Polzin, K.L., J.M. Toole, J.R. Ledwell, and R.W. Schmitt. 1997. Spatial variability of turbulent mixing in the abyssal ocean. Science 276(5309):93-96, https://doi.org/10.1126/science.276.5309.93.

Pratt, L.J. 1984. On nonlinear flow with multiple obstructions. Journal of the Atmospheric Sciences 41(7):1,214-1,225, https://doi.org/10.1175/1520-0469(1984)041 $<$ 1214:ONFWMO>2.0.CO;2.

Pratt, L.J., G. Voet, A. Pacini, S. Tan, M.H. Alford, G.S. Carter, J.B. Girton, and D. Menemenlis 2019. Pacific abyssal transport and mixing: Through the Samoan Passage versus around the Manihiki Plateau. Journal of Physical Oceanography 49(6):1,577-1,592, https://doi.org/ 10.1175/JPO-D-18-0124.1.

Reid, J.L., and P.F. Lonsdale. 1974. On the flow of water through the Samoan Passage. Journal of Physical Oceanography 4(1):58-73, https://doi.org/10.1175/1520-0485(1974)004 $<0058$ :OTFOWT $>2.0 . \mathrm{CO} \cdot 2$

Roemmich, D., S. Hautala, and D.L. Rudnick. 1996. Northward abyssal transport through the Samoan passage and adjacent regions. Journal of Geophysical Research 101(C6):14,039-14,055, https://doi.org/10.1029/96JC00797.

Rudnick, D.L. 1997. Direct velocity measurements in the Samoan Passage. Journal of Geophysical Research 102(C2):3,293-3,302, https://doi.org/ 10.1029/96JC03286.

Sánchez-Garrido, J.C., G. Sannino, L. Liberti, J. Garcia Lafuente, and L.J. Pratt. 2011. Numerical modeling of three-dimensional stratified tidal flow over Camarinal Sill, Strait of Gibraltar. Journal of Geophysical Research 116(C12), https://doi.org/ 10.1029/2011JC007093.

Shay, T.J., and M.C. Gregg. 1986. Convectively driven turbulent mixing in the upper ocean. Journa of Physical Oceanography 16(11):1,777-1,798, https://doi.org/10.1175/1520-0485(1986)016 $<1777$ : CDTMIT>2.0.CO:2.

Thorpe, S.A. 1977. Turbulence and mixing in a Scottish Loch. Philosophical Transactions of the Royal Society of London A 286:125-181, https://doi.org/ 10.1098/rsta.1977.0112

Voet, G., J.B. Girton, M.H. Alford, G.S. Carter, J.M. Klymak, and J.B. Mickett. 2015. Pathways, volume transport and mixing of abyssal water in the Samoan Passage. Journal of Physical Oceanography 45(2):562-588, https://doi.org/ 10.1175/JPO-D-14-0096.1.

Voet, G., M.H. Alford, J.B. Girton, G.S. Carter, J.B. Mickett, and J.M. Klymak. 2016. Warming and weakening of the abyssal flow through Samoan Passage. Journal of Physical Oceanography 46(8):2,389-2,401, https://doi.org/ 10.1175/JPO-D-16-0063.1.

Waterhouse, A.F., J.A. MacKinnon, J.D. Nash, M.H. Alford, E. Kunze, H.L. Simmons, K.L. Polzin, L.C. St. Laurent, O.M. Sun, R. Pinkel, and others. 2014. Global patterns of diapycnal mixing from measurements of the turbulent dissipation rate. Journal of Physical Oceanography 44(7):1,854-1,872, https://doi.org/ 10.1175/JPO-D-13-0104.1.

Wesson, J.C., and M.C. Gregg. 1994. Mixing at Camarinal Sill in the Strait of Gibraltar. Journal of Geophysical Research 99(C5):9,847-9,878, https://doi.org/10.1029/94JC00256.

Winters, K.B. 2016. The turbulent transition of a supercritical downslope flow: Sensitivity to downstream conditions. Journal of Fluid Mechanics 792:997-1,012, https://doi.org/10.1017/ jfm.2016.113.

\section{ACKNOWLEDGMENTS}

This work was funded by the National Science Foundation under grants OCE-1029268, OCE-1029483, OCE-1657264, OCE-1657870, OCE-1658027, and OCE-1657795

The authors thank Andrew Cookson for his expertise in maintaining the VMP. These measurements would not have been possible without the assistance of Alofa Aleta, Tahmeena Aslam, Eric Boget, Thomas Decloedt, Sam Fletcher, Deepika Goundar, Trina Lichtendorf, Janna Köhler, Keith Magness, Zoë Parsons, Andy Pickering, Tessa Tafua, and Vaatele Tauinaola. The authors would also like to thank Wes Hill, Eric Haroldson, and their crews aboard R/V Revelle and R/V Thompson, respectively, for their skill in ship handing and operations. Clément Vic and an anonymous reviewer are thanked for their thoughtful reviews.

The data are available through the microstructure archive: https://microstructure.ucsd.edu.

\section{AUTHORS}

Glenn S. Carter (gscarter@hawaii.edu) is Associate Professor, Department of Oceanography, University of Hawai'i at Mānoa, Honolulu, HI, USA. Gunnar Voet is Assistant Project Scientist, Scripps Institution of Oceanography, University of California San Diego (SIO-UCSD), La Jolla, CA, USA. Matthew H. Alford is Professor, SIO-UCSD, La Jolla, CA, USA. James B. Girton is Principal Oceanographer, Applied Physics Laboratory, University of Washington, Seattle, WA, USA. John B. Mickett is Senior Oceanographer, Applied Physics Laboratory, University of Washington, Seattle, WA, USA. Jody M. Klymak is Professor, University of Victoria, Victoria, British Columbia, Canada. Larry J. Pratt is Senior Scientist, Woods Hole Oceanographic Institution, Woods Hole, MA, USA. Kelly A. Pearson-Potts is Recent PhD, Department of Oceanography, University of Hawai'i at Mānoa, Honolulu, HI, USA. Jesse M. Cusack is Postdoctoral Researcher, SIO-UCSD, La Jolla, CA, USA. Shuwen Tan is a visiting PhD candidate, Woods Hole Oceanographic Institution, Woods Hole, MA, USA

\section{ARTICLE CITATION}

Carter, G.S., G. Voet, M.H. Alford, J.B. Girton, J.B. Mickett, J.M. Klymak, L.J. Pratt, K.A. PearsonPotts, J.M. Cusack, and S. Tan. 2019. A spatial geography of abyssal turbulent mixing in the Samoan Passage. Oceanography 32(4):194-203, https://doi.org/10.5670/oceanog.2019.425.

\section{COPYRIGHT \& USAGE}

This is an open access article made available under the terms of the Creative Commons Attribution 4.0 International License (https://creativecommons.org/ licenses/by/4.0/), which permits use, sharing, adaptation, distribution, and reproduction in any medium or format as long as users cite the materials appropriately, provide a link to the Creative Commons license, and indicate the changes that were made to the original content. 